\title{
The SAD Cycle for the Bucharest Stock Exchange
}

\author{
Razvan STEFANESCU \\ rzvn_stefanescu@yahoo.com \\ Ramona DUMITRIU \\ ramona_dumitriu@yahoo.com \\ "Dunarea de Jos" University of Galati, Romania
}

\begin{abstract}
The SAD effect is a calendar anomaly linked to the few length of the daylight during the autumn and the winter. In this paper we investigate the presence of this seasonal effect on the Romanian capital market. We find evidences of a significant SAD effect for an important index of the Bucharest Stock Exchange. We also identify some differences of this anomaly from before and during the crisis.
\end{abstract}

Keywords: Behavioral finance, Calendar anomalies, Seasonal affective disorder, Romanian capital market

JEL Code: G14

\section{Introduction}

The seasonal effects on the stock markets are among the main topics of the behavioral finance. They play a major role in some investment decisions. An investor who identified such calendar anomalies could use them to beat the market. The seasonal effects were used as arguments against the Efficient Market Hypothesis (EMH) which stipulated that past prices of the stocks couldn't be used to predict the future prices (Fama, 1970). However, recent versions of EMH admitted the calendar anomalies presence, but only a temporary one (Fama, 1998). They associated to any seasonal effect a life cycle ending with disappearance. Sometimes, extraordinary events, such as the financial crisis, interfere in that life cycle (Steeley, 2001.

Kamstra et al. (2003) introduced the SAD effect which is materialized in significant patterns of the stocks returns from the seasons of relatively fewer hours of daylight. They studied the evolution of indexes from United States, Sweden, Britain, Germany, Canada, New Zealand, Japan, Australia and South Africa, finding evidences in favor of the SAD effect presence. They also found the effect was greater as the distance from Equator was greater so the night length was bigger. This calendar anomaly was linked with the concept of seasonal affective disorder (SAD) which was defined by psychologists as a form of depression caused by the diminishing hours of daylight during the fall and winter months. Eisenberg et al. (1998) documented a strong relationship between the depression and the risk attitude. Garrett et al. (2003) suggested that even if daylight hours' decrease didn't provoke visible depression among the investors, it could affect instead their propensity to risks. Lo and Su (2008) found evidences that both financial analysts and investors were affected by the decrease of daylight. Some studies revealed particularities of SAD effect during the autumn in comparison with the winter days. It was hypothesized that in autumn, when the daylight was decreasing, the investors' tolerance to risk was different from winter, when the daylight was growing. Other researches found significant impact of the whether condition (sunshine, clouds, precipitation etc.) on the stock prices evolution (Hirshleife and Shumway, 2003; Saunders, 1993; Cao and Wei, 2005).

In this paper we investigate the SAD effect presence on the Romanian capital market. After a difficult start in 1990s, the Bucharest Stock Exchange (BSE) experienced an ascendant trend at the beginning of 2000s. Romania's adhesion to the European Union in 2007 attracted massive inflows of foreign investors who played a major role on the stock prices evolution. Since 2008, the global crisis affected BSE causing a major decline. Therefore we take into consideration the possibility that crisis induced changes in the SAD effect.

The rest of this paper is organized as follows. The second part describes the data and methodology employed to reveal the SAD effect on BSE. The third part presents the results of our investigation and the fourth part concludes. 


\section{Data and Methodology}

In our investigation we employ daily closing values of BET-C, an important index of BSE. Our sample covers a time period from January 2002 to September 2011 (Figure 1). In order to capture the changes induced by the global crisis we split that sample in two sub-samples:

- first sub-sample from 3rd January 2002 to 12 September 2008, corresponding to the pre-crisis period;

- second sub-sample, from $15^{\text {th }}$ September 2008 to $30^{\text {th }}$ September 2011, corresponding to the crisis period.

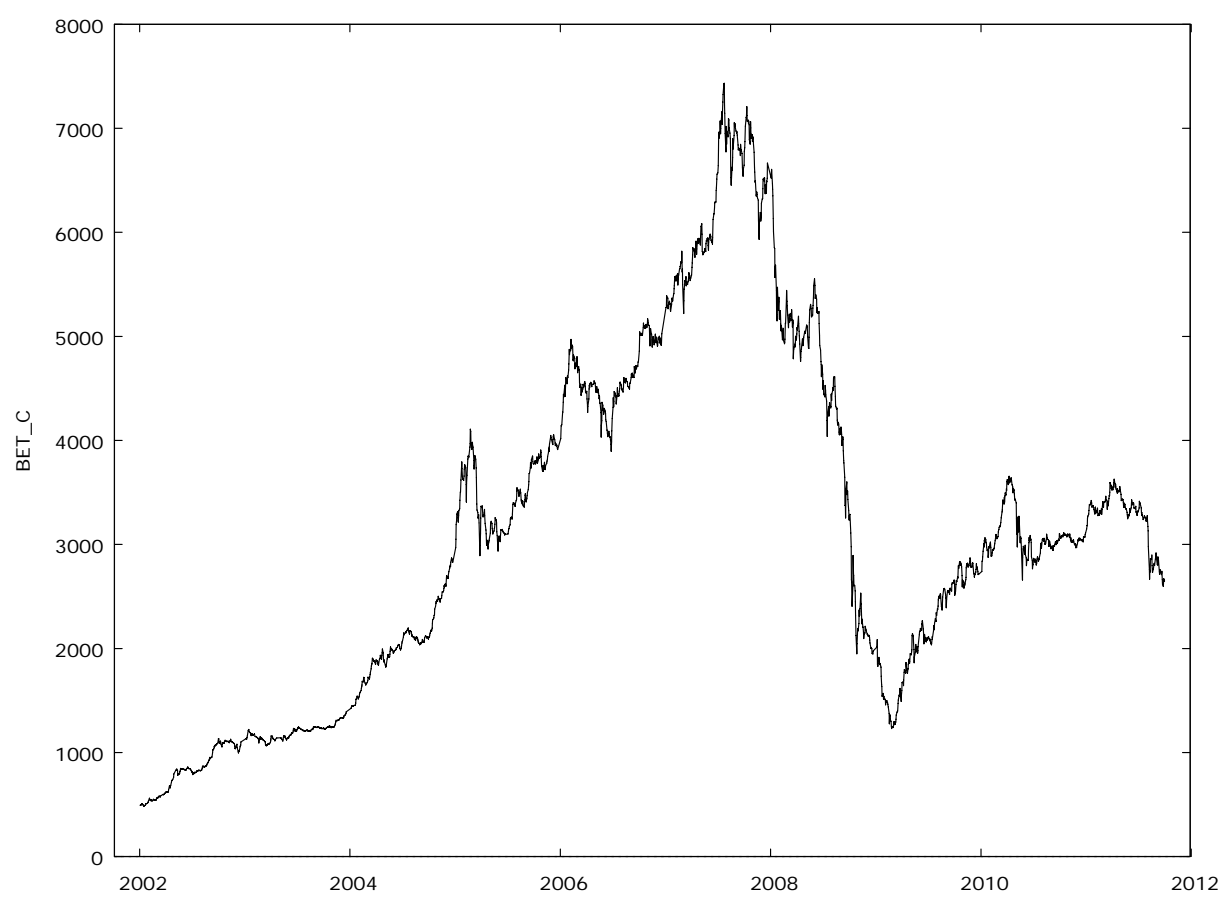

Figure 1 - Evolution of BET-C from January 2002 to September 2011

We calculate the returns of the BET-C index, using the formula:

where:

$$
\mathrm{R}_{\mathrm{t}}=\ln \left(\mathrm{P}_{\mathrm{t}}\right)-\ln \left(\mathrm{P}_{\mathrm{t}-1}\right)
$$

- $\quad \mathrm{R}_{\mathrm{t}}$ is the return on the day $\mathrm{t}$;

- $\quad \mathrm{P}_{\mathrm{t}}$ is the closing market index price on the day $\mathrm{t}$.

The descriptive statistics of BET-C returns, presented in the Table 1, revealed some significant differences between the two sub-samples. The average return from September 2008 to September 2011 was negative, as a consequence of the decline of BSE during the crisis. The standard deviation of returns increased from the first to the second sub-sample, reflecting the growing volatility of the stock prices. The results of Jarque-Bera Tests indicate the non normality of BET-C returns.

Table 1 - Descriptive statistics of BET-C returns

\begin{tabular}{|c|c|c|c|}
\hline Indicator & The full sample & First sub-sample & Second sub-sample \\
\hline Mean & 0.0696785 & 0.123260 & -0.0464834 \\
\hline Median & 0.106597 & 0.135650 & 0.0242512 \\
\hline Minimum & -12.1184 & -10.2876 & -12.1184 \\
\hline Maximum & 10.8906 & 5.22213 & 10.8906 \\
\hline Std. Dev. & 1.65009 & 1.35053 & 2.15793 \\
\hline Skewness & -0.709746 & -0.484120 & -0.650709 \\
\hline Ex. kurtosis & 7.55706 & 4.62723 & 5.77900 \\
\hline Jarque-Bera Test & 5993.71 & 1550.44 & 1122.9 \\
\hline p-values of & & & \\
Jarque-Bera Test & 0.000001 & 0.000001 & 0.000001 \\
\hline
\end{tabular}


We analyzed the stationarity of BET-C returns by Augmented Dickey-Fuller Tests. Based on the graphical representation we used a constant as deterministic term. The number of lags was chosen according to the Akaike Information Criterion. The results, presented in the Table 2, indicate that returns are stationary for all the three time periods.

Table 2 - Results of Augmented Dickey-Fuller Tests for BET-C returns

\begin{tabular}{|c|c|c|c|}
\hline Indicator & The full sample & First sub-sample & Second sub-sample \\
\hline Number of lags & 14 & 11 & 12 \\
\hline Test statistic & -8.38962 & -7.95007 & -4.4121 \\
\hline Asymptotic p-value & 0.000001 & 0.000001 & 0.000001 \\
\hline
\end{tabular}

We quantify the seasonal affective disorder circumstances by the number of night hours using the method applied by Kamstra et al. (2003). We calculate the sun's declination angle $\left(\lambda_{t}\right)$ using the formula:

$$
\lambda_{t}=0.4102 * \sin \left[\frac{2 \pi\left(\text { julian }_{t}-80.25\right)}{365}\right]
$$

where julian $_{t}$ is a variable representing the number of the day $t$ in the year.

For the Northern Hemisphere, the number of hours of night $\left(\mathrm{H}_{\mathrm{t}}\right)$ is calculated by formula:

$$
H_{t}=24-7.72 * \operatorname{arcos}\left[-\tan \left(\frac{2 \pi \delta}{360}\right) \tan \left(\lambda_{t}\right)\right]
$$

where $\delta$ is the latitude (we use latitude of 44 North degrees for Bucharest).

The night length for the latitude of 44 North degrees reaches a maximum of 15.216 hours in the winter solstice and a minimum of 8.53 hours in the summer solstice (Figure 2).

We use a variable, called $\mathrm{SAD}_{\mathrm{t}}$, to measure the seasonal affective disorder during the fall and the winter (we consider that fall starts on the fall equinox and it lasts until the winter solstice, while the winter starts on the winter solstice and it lasts until the spring equinox). This variable represents the length of the night in the fall and in the winter relative to the mean annual length considered to be of 12 hours, so $S_{A D}$ takes the value of $\left(H_{t}-12\right)$ for the trading days in the fall or in the winter and zero otherwise.

We try to reveal the SAD effect by employing a regression in which $R_{t}$ is the dependent variable and $S_{A D}$ is one of the independent variables. We also use in this regression dummy variables, reflecting the impact of the global crisis and the particularities of SAD effect during the fall. This regression is represented by equation:

$$
R_{t}=\gamma_{0}+\gamma_{1} \operatorname{SAD}_{t}+\gamma_{2} \text { FALL }_{t}+\gamma_{3} \operatorname{CRISIS}_{t}+\varepsilon_{t}
$$

where:

- FALL $L_{t}$ is a dummy variable taking the value one for the trading days during the fall and zero otherwise;

- $\quad$ CRISIS $_{t}$ is a dummy variable taking the value one for the trading days after $15^{\text {th }}$ September 2008 and zero otherwise.

In the case of autocorrelation or heteroskedasticity identified in that regression we use autoregressive terms to correct them. 


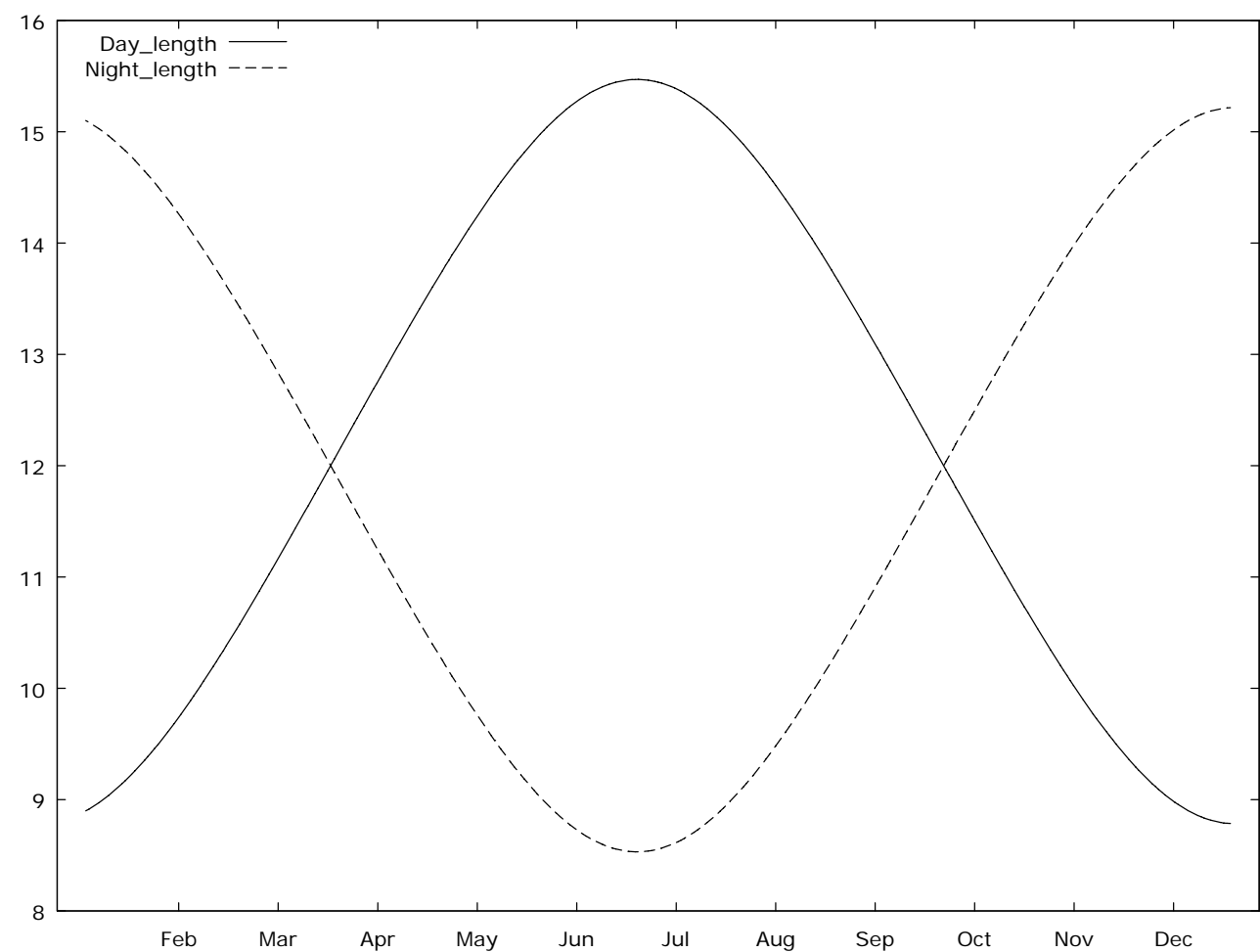

Figure 2 - Evolution of the day length and the night length during a year

\section{Empirical Results}

We calculate the descriptive statistics for two seasons: fall-winter and spring-summer. The results, presented in the Table 3, indicated that for all the three periods of time the returns from fallwinter were bigger than those from spring-summer.

Table 3 - Descriptive statistics of BET-C returns for the two seasons

\begin{tabular}{|c|c|c|c|}
\hline Indicator & The full sample & First sub-sample & Second sub-sample \\
\hline Panel A: Fall-Winter & & & \\
\hline Mean & 0.0328297 & 0.0696785 & -0.218872 \\
\hline Median & 0.110723 & 0.106597 & -0.0256025 \\
\hline Minimum & -12.1184 & -12.1183 & -12.1184 \\
\hline Maximum & 10.8906 & 10.8906 & 5.21955 \\
\hline Std. Dev. & 1.74703 & 1.65009 & 2.36366 \\
\hline Skewness & -0.925893 & -0.709746 & -0.878176 \\
\hline Ex. kurtosis & 8.13677 & 7.55706 & 6.11134 \\
\hline Panel B: Spring- & & & \\
\hline Summer & & & 0.0766515 \\
\hline Mean & 0.0998852 & 0.111594 & 0.117166 \\
\hline Median & 0.104900 & 0.104900 & -10.5036 \\
\hline Minimum & -10.5036 & -10.2876 & 9.25166 \\
\hline Maximum & 9.25166 & 10.8906 & 1.99168 \\
\hline Std. Dev. & 1.56617 & 1.30123 & -0.297928 \\
\hline Skewness & -0.443913 & -0.591071 & 4.53436 \\
\hline Ex. kurtosis & 6.48707 & 6.15325 & \\
\hline
\end{tabular}

We tested, for all the three time periods, the null hypothesis that differences of means for the two seasons are equal to zero. According to $t$ tests, that hypothesis could be rejected only for the second subsample. We also tested the null hypothesis that variances of the two seasons are equal and $\mathrm{F}$ tests indicated the null hypothesis could be rejected for all the three periods of time (Table 4). 
Table 4 - Results of the tests about the equality between means and variances for the two seasons

\begin{tabular}{|c|c|c|c|}
\hline Indicator & The full sample & $\begin{array}{c}\text { First sub- } \\
\text { sample }\end{array}$ & Second sub-sample \\
\hline$t$ tests for the zero difference & -0.997299 & -0.683656 & -1.87412 \\
between means & {$[0.1594]$} & {$[0.2471]$} & {$[0.03065]$} \\
\hline F tests for the equality between & 1.24429 & 1.60809 & 1.40841 \\
variances & {$[0.000001]$} & {$[0.000001]$} & {$[0.0004323]$} \\
\hline
\end{tabular}

Table 5 - Results of the regression for the full sample

\begin{tabular}{|c|c|c|c|c|}
\hline Variable & Coefficient & Std. Error & $\mathbf{z}$ & p-value \\
\hline const & 0.140227 & 0.03053 & 4.5925 & $0.00001^{* * *}$ \\
\hline SAD $_{\mathrm{t}}$ & 0.0596941 & 0.0244317 & 2.4433 & $0.01455^{* *}$ \\
\hline FALL $_{\mathrm{t}}$ & -0.109786 & 0.0590379 & -1.8596 & $0.06295^{*}$ \\
\hline CRISIS $_{\mathrm{t}}$ & -0.126127 & 0.052444 & -2.4050 & $0.01617^{* *}$ \\
\hline $\mathrm{ARCH}(0)$ & 0.0630782 & 0.0151429 & 4.1655 & $0.00003^{* * *}$ \\
\hline ARCH(1) & 0.2281 & 0.0258993 & 8.8072 & $0.00001^{* * *}$ \\
\hline GARCH(1) & 0.7719 & 0.0236472 & 32.6423 & $0.00001^{* * *}$ \\
\hline
\end{tabular}

For the regression (4) we identified by tests the presence of autocorrelation and heteroskedasticity, so we used ARCH terms. The results, presented in the Table 6, allowed us to identify a significant impact for all the independent variables.

We also perform the regression for the two sub-samples (obviously, in that case, the dummy variable $\mathrm{CRISIS}_{\mathrm{t}}$ was eliminated). For the first sub-sample we identify again a significant impact for all the independent variables.

Table 6 - Results of the regression for the first sub-sample

\begin{tabular}{|c|c|c|c|c|}
\hline Variable & Coefficient & Std. Error & $\mathbf{z}$ & p-value \\
\hline const & 0.115593 & 0.032004 & 3.6118 & $0.00030^{* * *}$ \\
\hline SAD $_{\mathrm{t}}$ & -0.134268 & 0.0679724 & -1.9753 & $0.04823^{* *}$ \\
\hline FALL $_{\mathrm{t}}$ & 0.098654 & 0.0280808 & 3.5132 & $0.00044^{* * *}$ \\
\hline $\mathrm{ARCH}(0)$ & 0.0829545 & 0.0233378 & 3.5545 & $0.00038^{* * *}$ \\
\hline $\mathrm{ARCH}(1)$ & 0.246946 & 0.0361138 & 6.8380 & $0.00001^{* * *}$ \\
\hline GARCH(1) & 0.736216 & 0.0360968 & 20.3956 & $0.00001^{* * *}$ \\
\hline
\end{tabular}

In the Table 7 there are presented the results of the regression for the second sub-sample. They indicate that nor $\mathrm{SAD}_{\mathrm{t}}$ neither $\mathrm{FALL}_{\mathrm{t}}$ has a significant influence on the dependent variable.

Table 7 - Results of the regression for the second sub-sample

\begin{tabular}{|c|c|c|c|c|}
\hline Variable & Coefficient & Std. Error & z & p-value \\
\hline const & 0.0920911 & 0.0614674 & 1.4982 & 0.13408 \\
\hline SAD $_{\mathrm{t}}$ & -0.0282004 & 0.122153 & -0.2309 & 0.81742 \\
\hline FALL $_{\mathrm{t}}$ & -0.0493053 & 0.0504683 & -0.9770 & 0.32859 \\
\hline $\mathrm{ARCH}(0)$ & 0.0647113 & 0.0282886 & 2.2875 & $0.02216^{* *}$ \\
\hline $\mathrm{ARCH}(1)$ & 0.209878 & 0.0367081 & 5.7175 & $0.00001^{* * *}$ \\
\hline GARCH(1) & 0.790122 & 0.0343308 & 23.0149 & $0.00001^{* * *}$ \\
\hline
\end{tabular}




\section{Conclusions}

In this paper we investigated the presence of SAD effect on BSE. The results of a regression with dummy variables revealed a significant influence of the night length on the BET-C returns. We found also that SAD effect from autumn is different than the one from winter.

The global crisis also influenced this calendar anomaly causing a decline. We could speculate that for almost the whole period of crisis, most of investors were rather pessimists and they avoided the risks, so the influence of SAD effect was not very obvious.

In the case of a small economy like Romania we should take into consideration the influence of other financial markets from industrialized countries. Since many important international financial centers are at closely latitude to Romania, it is possible that SAD effects from BSE to be in fact induced by other stock markets.

This analysis could be extended to other calendar anomalies that could interfere with the SAD effect. We could also include other factors like sunshine, clouds, temperature or precipitations that could influence the investors' behavior.

\section{References}

1. Cao, M., Wei, J. (2005), Stock market returns: A note on temperature anomaly. Journal of Banking \& Finance, 29 (6), pp. 1559-1573

2. Dimson E. and P. Marsh (1999), Murphy's Law and Market Anomalies, Journal of Portfolio Management 25(2) pp. 53-69

3. Eisenberg A.E., Baron J., Seligman M. (1998), Individual Differences in Risk Aversion and Anxiety, Working Paper, University of Pennsylvania, Department of Psychology

4. Fama E. (1970), Efficient capital markets: a review of theory and empirical work, Journal of Finance, No: 25, 383-41

5. Fama, E. (1998), Market Efficiency, Long-Term Returns and Behavioural Finance, Journal of Financial Economics, 49, pp. 283-306

6. Garrett Ian, Kamstra Mark, Kramer Lisa (2003), A SAD Day for Behavioral Finance? Winter Blues and Time Variation in the Price of Risk, January

7. Hirshleifer, D., Shumway, T. (2003), Good day sunshine: Stock returns and the weather. The Journal of Finance 58 (3), pp. 1009-1032

8. Kamstra, M.J., Kramer, L.A., Levi, M.D. (2003), Winter blues: A SAD stock market cycle. American Economic Review 93 (1), pp. 324-343

9. Kin Lo, Serena Shuo Wu (2008), The impact of Seasonal Affective Disorder on financial analysts and equity market returns, Accounting Research Conference of the Universities of BC, Oregon, and Washington

10. Peterson D.R. (1990), Stock return seasonalities and earnings information, Journal of Quantitative Analysis, 25, pp. 74-86

11. Saunders, E.M., Jr. (1993), Stock prices and the Wall Street weather, American Economic Review 83 (5), 1337

12. Schwert G. W. (2002), Anomalies and Market Efficiency, Working Paper, The Bradley Policy Research Center, Financial Research and Policy, University of Rochester

13. Steeley J.M. (2001), A Note on Information Seasonality and the Disappearance of the Weekend Effect in the UK Stock Market, Journal of Banking and Finance 25(10), pp. 1941-1956 